\title{
Assessment of occupational stress and its associated factors among health care professionals working in Gurage Zone Public Hospitals in Southern Ethiopia
}

Demamu Haligamo ( $\square$ demamutagele756@gmail.com )

Arba Minch University

\section{Tanimo Haligamo}

Wolkite University

\section{Research Article}

Keywords: Occupation, Stress, Factors, Healthcare, Professionals

Posted Date: November 5th, 2021

DOl: https://doi.org/10.21203/rs.3.rs-1051454/v1

License: (1) This work is licensed under a Creative Commons Attribution 4.0 International License. Read Full License 


\section{Abstract}

Background: Job-related stress is harmful physical and emotional responses that occur when the requirements of the job don't match the capabilities and needs of the worker. Therefore, if work isn't properly managed, job stress can happen that leads to illness, absenteeism, high turnover, and decreased productivity that compromise provision of quality service to clients. Workers are backbones of countries development that are at risk of different occupational stresses. And, there's no information about job-related stress among healthcare professionals and predicting factors around the study area. So, this study is aimed to assess occupational related stress and predicting factors among health care professional working in Gurage Zone public hospitals, Southern Ethiopia by August 2021.

Method: Institutional based cross-sectional study was conducted to assess occupational related stress and predicting factors among health care professionals. A structured self-administered questionnaire was used to collect data from 345 study participants. The data was collected and analyzed by using Statistical Package for Social Science (SPSS) version.23. The association between dependent and independent variables were checked by using bivariate and multivariable logistic regression. Finally, descriptive writings, tables and graphs were used to describe study variables.

Result: The result showed that the prevalence of occupation (work-related) stress among healthcare professionals was $78.3 \%$. Wards in which healthcare professionals are working, position of healthcare professionals, working hour and work shift have significant association with stress status of respondents. When compared to Medical ward, professionals working in other wards were 1.62 times more likely to have stress [AOR $1.62(1.23,2.13)]$. Also, when compared to respondents who are working for 8 hour per day, those working more than 8 hour per day were 70 times more likely to have stress [AOR $70(85,582)$ ].

Discussion and Conclusion: According to this study three out of four respondents were found to have stress among healthcare professionals. Regular trainings for healthcare professional should be needed in public hospitals to reduce stresses.

\section{Introduction}

Stress is a term for describing individual's negative interpretation for a real or subjective event as a threatening factor, which causes fear or anger(1). Job related stress is defined as the harmful physical and emotional responses that occur when the requirements of the job do not match the capabilities, resources, or needs of the worker(2). It occurs when the demands of a working environment over power the capacities of workers to cope with. Work related stress (WRS) is the response that individuals may face when they have job demands and pressures that mismatched their knowledge and abilities $(3,4)$. Healthcare settings are particular risks for occupational stress, burnout and job dissatisfaction because of the increased patient load and the high patient to health professional ratios(5). In general, an imbalance between work demands and the capacity to cope with such demands will cause stress $(6,7)$. Impacts of stress in work were estimated to be approximately $\$ 5.4$ billion every year worldwide(8). Half a million employee in Britanie was facing stress at an ill-health causing level(9). 
Stress at workplace among health professionals predisposes to an inefficient organization, absenteeism from work, job dissatisfaction, and various physical, psychological as well as behavioral health problems. Work related stress causes physical and psychological disorders. It also causes change in a person's physiology that forces them to deviate from their normal functions and work environment(10). The effects of job stress are considered terrible to both employees and employers. For the organization, the results are disorganization, disruption in normal operations, and decrease in productivity. For the employee, the effects of job stress are more than that of the organization(11). Health care profession is generally considered a stressful and demanding profession(12). There is a number of evidence that health care profession is a stressful occupation, which can lead to disruptions in both psychological and physical health and can impair professional practice(13). Despite this, little has been done into this health issue. So, this study will assess occupational stress and its determinants among health care professionals.

Work related stress on nurses would lead to absenteeism and turnover, which would affect the quality of patient care. That result in increased mortality among patients, failure to rescue and patient dissatisfaction(14). Causes of stress in health care professionals include also physical labor, suffering and emotional demands of patients and families, work hours, shift work, interpersonal relationships like inter- and intra-professional conflict, and lack of supportive relationship or poor relationship with colleagues and supervisors are also potential sources of stress(15).

Stress is a nonspecific response of the body to any demand of change that have an impact on human conditions and health (16). Workplace stress occurs in all workers or employees and high among health-care professionals an important group that can be affected by workplace stress because of the nature of their work environment(17).

Impact of stress on health sector's employees is more prevalent due to environment complexity (18). Workplace stress can have a number of impacts on health including mental and behavioral disorders such as exhaustion, burnout, anxiety and depression, as well as other physical impairments such as cardio-vascular disease and musculoskeletal disorders(19). In addition, stress can result in work absences, higher turnover, early retirement, lower productivity, and lower quality of services or products (20).

Job related stress has been found to be one of the major health problems. Job related stress incurs economic costs on the society and influences physical and psychological health of health care professionals and it can lead to burnout of health care professionals as well as a negative attitude toward professional activities and lack of appropriate communications with the patients(21). Stress contributes to health problems in health care professionals and decreases their efficiency, imposing a direct economic cost on employers and great impact on patients $₫ \operatorname{care}(22)$.

The study conducted in Addis Ababa revealed that gender, work shift, illness, marital status, and work unit were significantly associated with workplace stress (23). A study conducted in Worabe, South West Ethiopia, pointed out that sex, age, religion, ethnicity, marital status, child rearing, professional qualification, monthly salary, work experiences and department of work were the contributing factor of workplace stress (24). The study done in Kampala Uganda also showed that work experience and number of children were significant risk factors of workplace stress(25). A study done in New Zealand showed that excessive paper work, health reforms, bureaucratic interference, excessive hours and on-call work were the major factors associated with workplace 
stress(26). Another study done in Melbourne, Australia stated that determinants of workplace stress were social support, nurse empowerment and self-determination(27). Similarly, a study done in Jordan revealed that workplace stress was highest among general practitioners, dentists, and pharmacists and lowest among physician specialists (9). Similarly, a study done in Iran concluded that the risk factors of workplace stress were gender, hospital ward and working shift (28).

In Ethiopia, a study conducted in Jima Zone south west Ethiopia showed an average overall job related stress level of $58.46 \pm 12.62$, Addis Ababa, $37.8 \%$ of nurses reported experiencing occupational stress and in East Gojjam Zone Public hospitals northwest Ethiopia, 57.3\% of nurses were occupationally stressful(29),(23),(30)).

With this regard, there are few studies conducted on job related stress and its predicting factors among healthcare professionals nationally and there are no specifically conducted study in Wolkite University public hospitals. Therefore, the objective of this study was to assess workplace stress and associated factors among health care professionals working in Wolkite University public hospitals. It could be used to guide preventive measures and to provide methods to reduce the job stress experienced by health care professionals in the study area.

\section{Method And Materials}

Gurage zone is one of the administrative zones in South Ethiopia. It has 13 districts and two town administrations. Wolkite town is the capital of Gurage zone. It is found $153 \mathrm{~km}$ southwest to Addis Ababa, the capital of Ethiopia. According to the 2007 national household census, Gurage zone has total population of $1,279,646$, of which 657,568 are women. The study was conducted in Wolkite University specialized teaching hospital, Butajira general hospital and Gunchire primary hospital in Gurage Zone, SNNP region, Ethiopia by 2021. Hospital based cross sectional study design was conducted.

The sample size for this study was calculated by using a single population proportion formula. To calculate the sample size, the prevalence rate of job related stress taken from the previous research is $48.6 \%$ (16). Our calculated sample size under objective 2 including non-response rate ni $=319 * 10 \%(31.9)+319=351$ which was used to conduct this study. Out the total sample size, the data for this study was collected from 345 respondents which were $98.3 \%$ response rate.

The hospitals were purposively selected from all hospitals in the zone for this study. Based on the number of health professionals working in the hospital, the sample size was proportional allocation for healthcare departments in each hospital. By simple random sampling technique data was collected from 345 health care professionals.

A structured self-administered questionnaire was used to collect data from study participants. The questionnaire was adapted from literatures with modification to this study setting. The questionnaire developed by English version translated into Amharic language and then back into English after language experts in both cases participated to check its consistency. The questionnaire consists of two parts. Socio-demographics and work characteristics information, and modified expanded nursing stress scale (ENSS) which measures job related stress. 
One day training was given for data collectors and pre-testing of questionnaire was done to ensure the quality of data at another hospital in the zone by using $5 \%$ of the sample size. Principal investigators and advisors did spot-checking and reviewing all the completed questionnaires to ensure completeness and consistency of the information that was collected. We are both the data collectors and principal investigators for our study. Data entry was started on the process of data collection time.

The coded data was entered in to statistical package for social sciences (SPSS) version 23 for data analysis. The association between dependent and independent variables was checked by using simple bivariate logistic regression at $p<0.25$ and those candidates selected were again analyzed by using multivariable logistic regression. The strength of association between the dependent and independent variables was determined by calculating the odds ratio. Finally, the variables which have significant association were identified on the basis of AOR with $95 \% \mathrm{Cl}$ and $\mathrm{p}<0.05$ in multivariable binary logistic regression. Descriptive writings, tables and graphs were used to describe study variables.

Ethical clearance letter was obtained from Wolkite University department of Nursing. During data collection, the purpose of the study was clearly explained to the participants and informed verbal consent was obtained from each study participant for the data collection. Issues of rights, privacy and confidentiality were ensured during data collection period. Confidentiality was kept by making anonymous and assuring information will not be accessible to anyone. Privacy was maintained by arranging silent and comfortable place to the interviewer and study subject. Participants were given the right to participate or not and to withdraw at any time when they feel discomfort.

The findings of this study was submitted and presented to Wolkite University, department of Nursing. Effort will be made to present this study in different symposiums. It will also be disseminated to interested institutions, and other concerned and interested organizations. Publication in peer reviewed, national or international journals will also be considered.

\section{Results}

From 351 total sample size 345 households were participated in this study with a response rate of $98.3 \%$. About 195 (56.5\%) of respondents are within the age range of 30-49 years. Among the respondents majority 228(66.1\%) were females and 191 (55.4\%) were bachelor degree holders. The marital status of respondents indicates that 174 (50.4\%) were single. One hundred eighty nine (54.8\%) of the respondents were followers of Orthodox Christianity followed by Muslims which accounts 88 (25.5\%). Regarding their ward, 140(40.6\%) of the respondents were from medical ward. Out of total respondents 188 (54.5\%) were working more than 8 hour per day (24 hours). The detail of respondents characteristics were described below in table 1.

Table 1: Socio-demographic Characteristics of study participants $(n=345)$ 


\begin{tabular}{|c|c|c|}
\hline Characteristics & Number & Percentage (\%) \\
\hline \multicolumn{3}{|l|}{ Sex } \\
\hline Male & 117 & 33.9 \\
\hline Female & 228 & 66.1 \\
\hline \multicolumn{3}{|l|}{ Age } \\
\hline $18-29$ & 150 & 43.5 \\
\hline $30-49$ & 195 & 56.5 \\
\hline \multicolumn{3}{|l|}{ Religion } \\
\hline Orthodox & 189 & 54.8 \\
\hline Muslim & 88 & 25.5 \\
\hline Protestant & 68 & 19.7 \\
\hline \multicolumn{3}{|l|}{ Marital status } \\
\hline Single & 174 & 50.4 \\
\hline Married & 171 & 49.6 \\
\hline \multicolumn{3}{|l|}{ Level of education } \\
\hline Diploma & 136 & 39.4 \\
\hline Bachelor & 191 & 55.4 \\
\hline Masters and above & 18 & 5.2 \\
\hline \multicolumn{3}{|l|}{ Do you have children } \\
\hline Yes & 124 & 35.9 \\
\hline No & 221 & 64.1 \\
\hline \multicolumn{3}{|l|}{ Monthly salary } \\
\hline Less than 6000 & 74 & 21.4 \\
\hline Greater or equal to 6000 & 271 & 78.6 \\
\hline \multicolumn{3}{|l|}{ Work experience } \\
\hline 2 year and below & 44 & 12.8 \\
\hline More than 2 year & 301 & 87.2 \\
\hline \multicolumn{3}{|l|}{ Ward/unit where you work } \\
\hline Medical ward & 140 & 40.6 \\
\hline Surgical ward & 76 & 22 \\
\hline Gynecology & 18 & 5.2 \\
\hline OPD & 64 & 18.6 \\
\hline Others & 47 & 13.6 \\
\hline \multicolumn{3}{|l|}{ Position } \\
\hline Staff & 210 & 60.9 \\
\hline Head of unit & 22 & 6.4 \\
\hline Matron nurse & 56 & 16.2 \\
\hline Supervisor & 8 & 2.3 \\
\hline Case team director & 49 & 14.2 \\
\hline \multicolumn{3}{|l|}{ Working hour } \\
\hline 8 hour & 157 & 45.5 \\
\hline Greater than 8 hour & 188 & 54.5 \\
\hline \multicolumn{3}{|l|}{ Work shift } \\
\hline Rotating & 288 & 83.5 \\
\hline Fixed & 157 & 16.5 \\
\hline \multicolumn{3}{|l|}{ Job satisfaction } \\
\hline No & 95 & 27.5 \\
\hline Yes & 250 & 72.5 \\
\hline \multicolumn{3}{|l|}{ Known chronic medical illness } \\
\hline No & 345 & 100 \\
\hline
\end{tabular}


Any medication for known chronic illness

\begin{tabular}{cll}
\hline No & 345 & 100 \\
\hline Any substance & & \\
No & 316 & 91.6 \\
\hline Yes & 29 & 8.4 \\
\hline Extra payment for additional load & & \\
No & 210 & 60.9 \\
\hline Yes & 135 & 39.1 \\
\hline
\end{tabular}

Individuals' responses to total questions modified from ENSS were used to assess the stress status of respondents. About a total of 53 questions were used with average mean score of 2.5 used as cut of point and those respondents scored 2.5 and above mean in the ENSS were categorized as stressed. The total respondents scored mean score of 2.5 and above were 270 (78.3\%), which were categorized as stressed.

The association between dependent and independent variables was checked by using bivariate logistic regression at $p<0.25$ and then candidates were selected for analysis by multivariable binary logistic regression. Based on this, out of total variables used, variables like marital status, ward/unit, working hour, position and work shift were identified as eligible by simple bivariate logistic regression for analysis by multivariable logistic regression. The strength of association between the dependent and independent variables was determined by calculating the odds ratio. Finally, the variables which have significant association were identified on the basis of AOR with $95 \% \mathrm{Cl}$ and $\mathrm{p}<0.05$ in multivariable logistic regression. By controlling confounding variables the result of multivariable logistic regression shows that except marital status the remaining four variables have significant association with stress status of respondents.

Accordingly, using binary logistic regression analysis, when compared to respondents who were single those married respondents were 1.76 times more likely to have stress [COR $1.76(1.044,2.967)]$. In the same way compared to respondents who are working for 8 hour per day, those working more than 8 hour per day were 2.27 times more likely to have stress [COR $2.27(1.35,3.84)]$. On the other hand, compared to fixed work shift, those respondents having rotating work shift were 0.184 times less likely to have stress [COR $0.184(0.10$, 0.34)]. In the same way, compared to professionals working as staff, professional in other working positions were 0.48 times less likely to have stress [COR $0.48(0.41,0.58)]$. Also, compared to Medical ward, professionals working in other wards were 0.82 times less likely to have stress [COR $0.82(0.76,0.89)]$.

Multiple logistic regressions analysis shows ward, position, working hour and work shift have significant association with stress status of respondents. The result shows, when compared to respondents who are working for 8 hour per day, those working more than 8 hour per day were 70 times more likely to have stress [AOR $70(85,582)]$. The reverse of simple binary logistic regression, when compared to Medical ward, professionals working in other wards were 1.62 times more likely to have stress [AOR $1.62(1.23,2.13)]$. On the other hand, compared to fixed work shift, those respondents having rotating work shift were 0.01 times less likely to have stress [AOR $0.01(0.001,0.02)]$. In the same way, compared to professionals working as staff, professional in other working positions were 0.01 times less likely to have stress [AOR $0.01(0.002,0.09)$ ] (See table 2). 
Table 2: Logistic regression analysis result showing association between variables

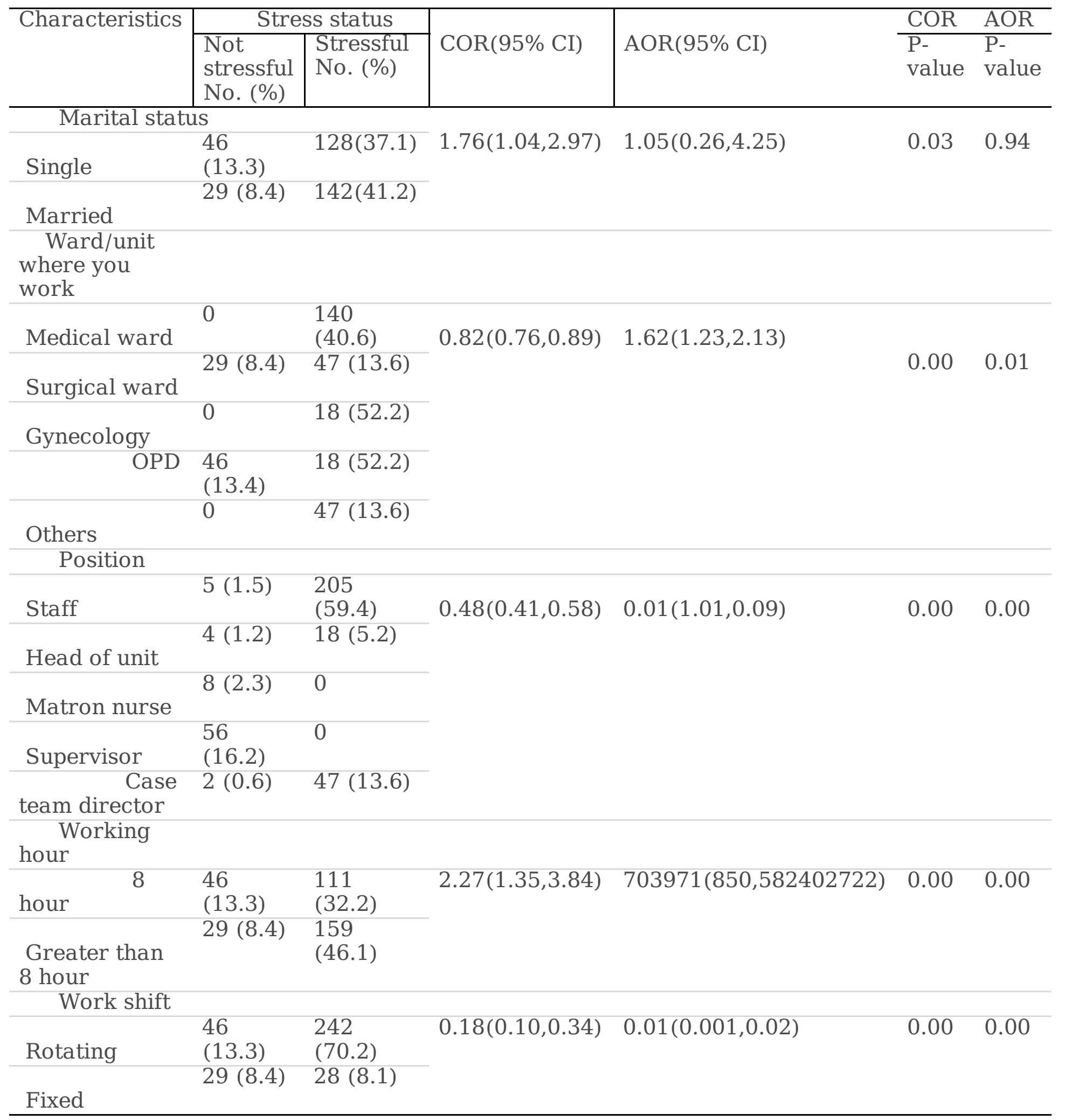

\section{Discussion And Conclusion}


The result of this study showed that about three fourth of the study participants have stress. Based on the result the working ward/unit and working hour are majorly identified as having a significant association and effect on stress status of health care professionals.

Based on our study, the prevalence of occupation (work related) stress is $78.3 \%$ which is higher than others study indifferent areas like among healthcare professionals working Addis Abeba public hospital 37.8\% (23), healthcare staff in Iran 34.9\%(33), healthcare professionals working Jima Zone public hospitals 58.46\%(29), healthcare professionals working in East Gojam Zone public hospitals 57\%(30) and based on national institute of occupational safety and health study $48.6 \%$. This high prevalence of work related occupational stress may be due to lack of occupational and environmental professionals working in the three hospitals our study conducted.

This study showed working hour/work load, work shift and work site/unit are identified as having significant association with work related stress which is similar to the studies like study conducted in Spain on three hospitals (workload)(40) and work shift and type of ward/unit were identified by study conducted at Addis Abeba public hospital (23). Based on our study, using rotating work shift and working for 8 hour are some factors that resulted in reducing stress among professionals participated under this study.

According to this study three out of four respondents were found to have stress among healthcare professionals. Multiple logistic regressions were used to determine wither a variable is a factor or not based on stress status of respondents. Ward/unit, position, work shift and working hour have significant association with stress. Multiple logistic regressions analysis shows ward, position, working hour and work shift have significant association with stress status of respondents.

The result shows, when compared to respondents who are working for 8 hour per day, those working more than 8 hour per day were more likely to have stress. When compared to Medical ward, professionals working in other wards were more likely to have stress. On the other hand, compared to fixed work shift, those respondents having rotating work shift were less likely to have stress. In the same way, compared to professionals working as staff, professional in other working positions were less likely to have stress.

\section{Strength of the study}

- Good response rate

\section{Limitation of the study}

- The questioner was mostly focused on stress assessment questions of nursing professionals stress status

\section{Recommendation}

- Awareness creation by hospitals should be needed for healthcare professional about the importance avoiding occupational stresses among healthcare professionals in the public hospitals.

- The public hospitals should have to employee occupation health and safety professionals to keep the health and safety of healthcare professionals in the public hospitals. 
- Reducing the working hour to 8 per day and using rotational work shift should be employed by the public hospitals to reduce occupational stress.

- Regular trainings for professional should be needed in public hospitals to reduce stress

- Doing future researches on stress among healthcare professionals in a public hospitals and clinics should be needed to increase the knowledge on stress and to fill any identified gaps.

\section{References}

1. Konstantinos N, Christina O. FACTORS INFLUENCING STRESS AND JOB SATISFACTION OF NURSES WORKING IN PSYCHIATRIC UNITS: A RESEARCH REVIEW. Health science journal. 2008;2(4).

2. Steege AL, Boiano JM, Sweeney MH. NIOSH health and safety practices survey of healthcare workers: training and awareness of employer safety procedures. American journal of industrial medicine. 2014;57(6):640-52.

3. Kabito GG, Wami SD. Perceived work-related stress and its associated factors among public secondary school teachers in Gondar city: a cross-sectional study from Ethiopia. BMC research notes. 2020;13(1):1-7.

4. Cavanaugh MA, Boswell WR, Roehling MV, Boudreau JW. An empirical examination of self-reported work stress among US managers. Journal of applied psychology. 2000;85(1):65.

5. Xie Z, Wang A, Chen B. Nurse burnout and its association with occupational stress in a cross-sectional study in Shanghai. Journal of advanced nursing. 2011;67(7):1537-46.

6. Payne R, Firth-Cozens J. Stress in health professionals: Psychological and organizational causes and interventions. Stress at work: A conceptual framework. 1999:3-16.

7. McVicar A. Workplace stress in nursing: a literature review. Journal of advanced nursing. 2003;44(6):633-42.

8. Lèfstedt R, Work GBf, Pensions. Reclaiming health and safety for all: An independent review of health and safety legislation. 2011.

9. Boran A, Shawaheen M, Khader Y, Amarin Z, Hill Rice V. Work-related stress among health professionals in northern Jordan. Occupational Medicine. 2012;62(2):145-7.

10. Paillé P. Stressful work, citizenship behaviour and intention to leave the organization in a high turnover environment: examining the mediating role of job satisfaction. Journal of Management Research. 2011;3(1):114.

11. Kossek EE, Pichler S, Bodner T, Hammer LB. Workplace social support and work-family conflict: A metaanalysis clarifying the influence of general and work-family-specific supervisor and organizational support. Personnel psychology. 2011;64(2):289-313.

12. Rogers B. Occupational and environmental health nursing: Concepts and practice: Elsevier Health Sciences; 2003. 
13. Al-Hawajreh K. Exploring the relationship between occupational stress and organizational commitment among nurses in selected jordanian hospitals. 2011.

14. Daouk-Öyry L, Anouze A-L, Otaki F, Dumit NY, Osman I. The JOINT model of nurse absenteeism and turnover: a systematic review. International journal of nursing studies. 2014;51(1):93-110.

15. Riggio R. Introduction to industrial and organizational psychology: Routledge; 2015.

16. Gebeyehu S, Zeleke B. Workplace stress and associated factors among healthcare professionals working in public health care facilities in Bahir Dar City, Northwest Ethiopia, 2017. BMC research notes. 2019;12(1):249.

17. Pisljar T, van der Lippe T, den Dulk L. Health among hospital employees in Europe: A cross-national study of the impact of work stress and work control. Social science \& medicine. 2011;72(6):899-906.

18. Elsayed F, Ahmed M, Gaheen M. Knowledge and Practices of women regarding risk factors of uterine prolapse. IOSR Journal of Nursing and Health Science (IOSR-JNHS). 2016;5(6):60-7.

19. ILO I. Workplace Stress: A Collective Challenge. Labour Administration, Labour Inspection and Occupational Safety and Health ...; 2016.

20. Parent-Thirion A, Fernández E, Hurley J, Vermeylen G. Fourth European Working Conditions Survey. Luxembourg: Office for Official Publications of the European Communities. Retrieved May-30-2008. 2007.

21. Rauhala A, FAGERSTRÖM L. Are nurses' assessments of their workload affected by non-patient factors? An analysis of the RAFAELA system. Journal of Nursing Management. 2007;15(5):490-9.

22. Onasoga OA, Osamudiamen OS, Ojo A. Occupational stress management among nurses in selected hospital in Benin city, Edo state, Nigeria. Eur J Exp Biol. 2013;3(1):473-81.

23. Salilih SZ, Abajobir AA. Work-related stress and associated factors among nurses working in public hospitals of Addis Ababa, Ethiopia: a cross-sectional study. Workplace health \& safety. 2014;62(8):326-32.

24. Anand S, Mejid A. Prevalence and associated factors of work related stress among nurses working in worabe comprehensive and specialized hospital, south west Ethiopia. Prevalence. 2018;3(3):260-6.

25. Nabirye RC, Brown KC, Pryor ER, Maples EH. Occupational stress, job satisfaction and job performance among hospital nurses in Kampala, Uganda. Journal of nursing management. 2011;19(6):760-8.

26. Dowell AC, Hamilton S, McLeod DK. Job satisfaction, psychological morbidity and job stress among New Zealand general practitioners. New Zealand Medical Journal. 2000;113(1113):269.

27. Bartram T, Joiner TA, Stanton P. Factors affecting the job stress and job satisfaction of Australian nurses: implications for recruitment and retention. Contemporary nurse. 2004;17(3):293-304.

28. Gorgich EAC, Zare S, Ghoreishinia G, Barfroshan S, Arbabisarjou A, Yoosefian N. Job stress and mental health among nursing staff of educational hospitals in South East Iran. Thrita. 2017;6(1):e45421. 
29. Dagget T, Molla A, Belachew T. Job related stress among nurses working in Jimma Zone public hospitals, South West Ethiopia: a cross sectional study. BMC nursing. 2016;15(1):39.

30. Haile D, Gualu T, Zeleke H, Dessalegn B. Job Satisfaction and Associated Factors among Nurses in East Gojjam Zone Public Hospitals Northwest Ethiopia, 2016. J Nurs Care. 2017;6(398):2167-1168.1000398.

31. Blaug R, Kenyon A, Lekhi R. Stress at work: A report prepared for the work foundation's principal partners. Project Report. The Work Foundation. 2007;2(2):143-8.

32. Griffith-Noble F. A multi-method investigation of the psychosocial work environment and nature of workrelated stress of NHS physiotherapists and occupational therapists: University of Nottingham; 2010.

33. Jose TT, Bhat SM. A descriptive study on stress and coping of nurses working in selected hospitals of Udupi and Mangalore districts Karnataka, India. IOSR Journal of Nursing and health science. 2013;3(1):10-8.

34. Al Sorihi SAAF. The association of external auditor's attributes with management fraud risk assessment in financial reporting: empirical evidence from Yemen: Universiti Utara Malaysia; 2013.

35. Phillips S, Sen D, McNamee R. Prevalence and causes of self-reported work-related stress in head teachers. Occupational medicine. 2007;57(5):367-76.

36. Wu H, Chi TS, Chen L, Wang L, Jin YP. Occupational stress among hospital nurses: cross-sectional survey. Journal of advanced nursing. 2010;66(3):627-34.

37. French SE, Lenton R, Walters V, Eyles J. An empirical evaluation of an expanded nursing stress scale. Journal of nursing measurement. 2000;8(2):161-78.

38. Mozhdeh S, Sabet B, DOUSTI IM, Hajian E, Malbousizadeh M. Relationship of nurse's stress with environmental-occupational factors. 2008.

39. Hashemian SMR, Farzanegan B, Fathi M, Ardehali SH, Vahedian-Azimi A, Asghari-Jafarabadi M, et al. Stress among Iranian nurses in critical wards. Iranian Red Crescent Medical Journal. 2015;17(6).

40. Mansour SE, Elnegeri MA, Ibrahim A. Chewing gum after cesarean section: it's effect on regaining intestinal function. IOSR Journal of Nursing and Health Science (IOSR-JNHS). 2016;5(6):75-83.

41. Abd El-Raheem GO. Practice of Hyperglycaemia Control in Intensive Care Units of the Military Hospital, Sudan-Needs of a Protocol. medRxiv. 2020.

\section{Declarations}

\section{Acknowledgement}

First, we are thanksgiving for divine favor in everything. Then, we would like to recognize Wolkite University College of Medicine and Health Sciences, department of nursing, for giving us an opportunity to conduct this research. Our appreciation also goes to our advisors Mr. Zebene M. and Mr. Haile W. for their support through advice and provision of important information's during the research development process. We also give thanks 
to study participants and university community for participating and supporting the development of this research. 